\title{
USO DE SIMULAÇÕES COMPUTACIONAIS EM AULAS DE FÍSICA: UM ESTUDO SOBRE A SUA INFLUENCIA NO PROCESSO DE APRENDIZAGEM DOS ESTUDANTES COM DEFICIÊNCIA
}

\author{
The use of Computer Simulations in Physics Classes: a Study on the Influence of the \\ Learning Process for Students with Disabilities
}

Patrícia Sousa Carvalho ${ }^{1}$

Ana Carolina Sales Oliveira ${ }^{2}$

\begin{abstract}
Resumo: Uma das alternativas para auxiliar o professor no processo de inclusão do estudante com deficiência é o uso das Tecnologias de Informação e Comunicação (TIC), uma vez que esses recursos podem criar situações de aprendizagens mais equitativas. Sendo assim, o presente artigo tem por objetivo compreender as potencialidades do uso das TIC, especificamente das simulações computacionais, para o processo de aprendizagem dos estudantes com deficiência, nas aulas de Física de uma escola regular da educação básica. A pesquisa é de cunho qualitativo, fundamentada principalmente nas pesquisas de Flick (2009). A análise do estudo se deu a partir dos dados obtidos por meio de diário de campo, questionários, atividades realizadas pelos estudantes e gravações, todos realizados durante o desenvolvimento das atividades relacionadas à essa pesquisa. Observou-se, ao longo das intervenções, que os recursos tecnológicos favoreceram o processo de aprendizagem, trazendo maior significação aos conteúdos abordados, possibilitando que a aprendizagem fosse realizada de maneira lúdica, bem como uma alternativa para o estudante sair da posição passiva da construção do seu conhecimento e ser um agente ativo, o que se entende ser importante para uma aprendizagem efetiva. Além disso, as simulações computacionais se configuraram como recursos válidos para facilitar e superar algumas limitações dos estudantes com deficiência. Por fim, a pesquisa mostrou que estratégias didáticas aliadas a tecnologias digitais são significativas para o processo de aprendizagem dos estudantes.
\end{abstract}

Palavras-chave: Educação Inclusiva. Simulações Computacionais. Ensino de Física.

\begin{abstract}
An alternative to assist in the inclusion process of students with disabilities is to use Information and Communication Technologies (ICT), since these resources can create more equitable learning situations. Therefore, this paper aims to understand the potentialities of the use of ICT, more specifically, of computer simulations in the learning process of students with disabilities during physics classes in a regular elementary school. The research is of a qualitative approach, based mainly on the research of Flick (2009). The analysis presented in this study was based on the data obtained from field diary, questionnaires,

\footnotetext{
${ }^{1}$ Graduada em Física Licenciatura pela Universidade Federal de Itajubá (UNIFEI), mestranda do Programa de Pós-Graduação em Educação em Ciências pela UNIFEI. Orcid: https://orcid.org/0000-0001-8225-7579. E-mail: psousac16@gmail.com.

${ }^{2}$ Graduada em Fonoaudiologia pela Pontifícia Universidade Católica de Campinas (2005) e Pedagogia pela Universidade Paulista (2014). Mestra e Doutora em Ciências da Linguagem (CAPES 4) pela Universidade do Vale do Sapucaí. Professora da disciplina LIBRAS, na Universidade Federal de Itajubá (UNIFEI). Orcid: https://orcid.org/0000-0003-1891-4567. E-mail: anacarolinasales@unifei.edu.br.
} 
activities carried out by the students and recordings made during the development of activities related to this research. It was observed, throughout the interventions, that technological resources favored the learning process, bringing greater significance to the content covered, allowing the apprenticeship to be carried out in a playful way, as well as an alternative for the students to leave a passive position in the construction of their knowledge and be an active agent, which is considered to be important for effective learning. Furthermore, computer simulations have been shown to be a valid resource for facilitating and overcoming some limitations of students with disabilities. Finally, the research has shown that didactical strategies allied with digital technologies are significant for the students' learning process.

Keywords: Inclusive Education. Computational Simulation. Physics Teaching.

\section{Introdução}

No Brasil e no mundo, mudanças no processo de inclusão dos estudantes com deficiência são respaldadas por leis, decretos e portarias que regem toda a norma da educação. Entende-se que a Declaração de Salamanca foi um marco importante para a Educação Inclusiva, pela preocupação com a inserção dos "[...] jovens e adultos com necessidades educacionais especiais dentro do sistema regular de ensino" (BRASIL, 1994, p. 1), pois, para que os estudantes com deficiência sejam incluídos, faz-se necessária a reformulação do processo de ensino, visando a uma educação para todos e fazendo com que o princípio da inclusão seja defendido como proposta de aplicação prática no campo da educação.

Nessa perspectiva, Mendes (2006) ressalta que os fundamentos da inclusão pressupõem que as diferenças humanas são normais, mas reconhece a necessidade de uma reformulação do contexto escolar, com o objetivo de promover uma educação de qualidade para todos os estudantes, independentemente de sua condição. Nesse sentido, Mantoan (2003) destaca que é preciso ensinar a turma toda, partindo do pressuposto de que "[...] todo educando pode aprender, mas no tempo e do jeito que lhe é próprio" (p. 38).

Deve-se ressaltar que a Educação Inclusiva não é voltada apenas para os estudantes com deficiência, mas para todos os estudantes, "[...] independentemente de seu talento, deficiência, origem socioeconômica ou origem cultural" (KARAGIANNIS; STAIBACK; STAIBACK, 1999, p. 21), isto é, uma escola que preza por um ensino inclusivo, que remove barreiras e proporciona a participação plena dos estudantes, beneficia a todos. No entanto, a presente pesquisa apresenta uma discussão voltada especificamente para os estudantes com deficiência e/ou transtorno.

Uma alternativa que pode ser utilizada para auxiliar no processo de inclusão de todos os estudantes é o uso das Tecnologias de Informação e Comunicação (TIC), que, segundo Coll e Monereo (2010), são ferramentas que têm a capacidade de representar e transmitir alguma informação por meio de sistemas de signos.

Autores como Giroto, Poker e Omote (2012) ressaltam o uso das Tecnologias de Informação e Comunicação (TIC), uma vez que tais ferramentas podem trazer algumas vantagens, como:

[...] a individualização do ensino respeitando o ritmo e o tempo de realização de atividade de cada aluno; a flexibilidade que viabiliza o uso de canais sensoriais distintos; a avaliação contínua e dinâmica; a autoavaliação; a manutenção da mesma atividade/exercício de acordo com as necessidades educacionais do aluno; o ajuste do nível de complexidade da atividade; o desenvolvimento de hábitos e de disciplina para sua utilização; a motivação, pois podem ser inseridos temas, cores, figuras, formas que atendem aos interesses dos alunos estimulando-os, de diferentes 
maneiras, a realizar as atividades propostas, entre outras (GIROTO; POKER; OMOTE, 2012, p. 21).

Nessa perspectiva, Coll e Monereo (2010) destacam que as TIC podem possibilitar a oportunidade de oferecer aos estudantes uma educação de qualidade, baseada nos princípios de solidariedade e igualdade. Consoante a isso, Souza (2015) destaca que as TIC surgem apontando uma possibilidade de inclusão e autonomia dos estudantes nos ambientes escolares.

Entende-se, assim, que o uso desses recursos tecnológicos tem a potencialidade de estimular os sentidos e o compartilhamento de informações, além de apontar novas formas de relacionamento, de comunicação e de construção de conhecimentos que, consequentemente, podem abrir novas possibilidades pedagógicas. Dessa forma, as TIC vêm sendo utilizadas a favor da educação de todos os estudantes, em especial dos que apresentam alguma dificuldade de aprendizagem, uma vez que são capazes de possibilitar o "[...] acesso às informações, acesso aos conteúdos curriculares, bem como a organização diferenciada das atividades de forma a atender as condições e características do aluno, ou seja, às suas especificidades" (GIROTO; POKER; OMOTE, 2012, p. 17).

Dentre os recursos advindos das TIC, destacam-se, neste estudo, as simulações computacionais que fazem uso de animações alternativas, selecionadas por meio da alteração de parâmetros. Nesse sentido, a utilização dessas simulações se torna uma importante ferramenta para o processo de ensino e aprendizagem, já que pode possibilitar a interação do estudante com o objeto de estudo (MEDEIROS; MEDEIROS, 2002).

Diante do exposto, o presente estudo tem por objetivo compreender as potencialidades do uso das TIC, especialmente das simulações computacionais, para o processo de aprendizagem dos estudantes - em específico dos estudantes Público-Alvo da Educação Especial (PAEE) -, nas aulas de Física de uma escola regular da educação básica.

\section{Simulações computacionais no ensino de Física}

A Física envolve diversos conceitos, alguns deles caracterizados pela abstração, o que torna o ensino da disciplina uma tarefa desafiadora para os professores. De acordo com Medeiros e Medeiros (2002, p. 78), para contornar essa situação os professores complementam a linguagem verbal, a escrita e a Matemática com o uso de "[...] recursos ao real concreto e às imagens".

No entanto, segundo os autores supracitados, a abstração dos conceitos persiste ao representar movimentos com imagens estáticas. Nessa perspectiva, de acordo com os pensamentos de Macêdo e Dickman (2009), Medeiros e Medeiros (2002) e Costa (2017), a partir das animações produzidas, as simulações computacionais se configuram como uma das alternativas para tornar o ensino da Física mais interativo e menos abstrato.

Macêdo e Dickman (2009) ressaltam que as simulações computacionais podem reproduzir de forma digital um processo ou operação do mundo real, o que muitas vezes não seria possível em um laboratório tradicional, seja por falta de estrutura ou por inviabilidades relacionadas a determinados experimentos. Da mesma maneira, os estudantes têm a possibilidade de aprender sobre os fenômenos físicos do mundo em que vivem, relacionando-os ao seu cotidiano - fenômenos que não poderiam ser inferidos por meio da observação direta (MEDEIROS; MEDEIROS, 2002).

As simulações computacionais podem ainda propiciar uma ponte entre o estudo do fenômeno - da maneira tradicional - e os experimentos de laboratório, pois permitem que os resultados 
obtidos por meio das simulações computacionais sejam vistos com clareza, por diversas vezes e com grande número de variáveis envolvidas (COELHO, 2002).

Nesse sentido, a utilização das simulações computacionais em contexto escolar tem sido defendida, visto que podem proporcionar um ambiente interativo tanto entre o estudante e o objeto de estudo quanto entre os estudantes e seus colegas e/ou professores, o que pode se configurar como fundamental para a aprendizagem de determinados conceitos (COSTA, 2017).

Costa (2017) destaca ainda que as simulações computacionais permitem que os estudantes obtenham um feedback rápido e que, por meio desses resultados, possam avançar no processo de aprendizagem de acordo com suas capacidades, desenvolvendo as habilidades e competências que são exigidas para o entendimento do conteúdo físico que está sendo abordado. Assim, entende-se que as simulações computacionais podem ser uma alternativa para respeitar o ritmo de aprendizagem dos estudantes, possibilitando um ensino que se molde às suas necessidades.

Desse modo, compreende-se que as simulações computacionais podem propiciar uma participação mais ativa dos estudantes frente ao processo de aprendizagem, pois, dependendo da forma como são utilizadas, podem levar o aluno a observar os modelos e fenômenos físicos, construir conceitos, coletar dados, elaborar e testar suas hipóteses, a fim de verificálas. Com isso, conclui-se que as simulações computacionais, variando de acordo com a forma como são utilizadas no âmbito educacional, podem possibilitar a oportunidade de respeitar as diferenças dos estudantes e criar ambientes de aprendizagem para cada um. Esses fatores favorecem a equiparação de oportunidades e a inclusão escolar dos estudantes com deficiência, bem como daqueles que tenham alguma dificuldade de aprendizagem.

Com base no exposto, torna-se tangível o grande potencial das simulações computacionais no auxílio à aprendizagem de todos os estudantes. Desse modo, a seguir serão apresentados o desenvolvimento e a implementação do conjunto de atividades que utilizam tais recursos em âmbito educacional.

\section{Caminhos percorridos}

Com vistas a atingir o objetivo da presente pesquisa, que consiste em compreender as potencialidades da utilização das simulações computacionais para o processo de aprendizagem dos estudantes PAEE nas aulas de Física de uma sala regular da educação básica, este estudo adotou uma abordagem de natureza qualitativa. Para Flick (2009, p. 8), a pesquisa qualitativa “[...] visa abordar o mundo 'lá fora' (e não em contextos especializados de pesquisa como os laboratórios) e entender, descrever e, às vezes, explicar os fenômenos", e pode ser realizada através de análise de experiências, examinando interações e comunicações.

O presente trabalho apresenta ainda algumas características da pesquisa qualitativa descritas por Creswell (2007), sendo elas: a coleta de dados no local onde a investigação ocorre; o pesquisador compreendido como instrumento fundamental, incumbido de realizar pessoalmente a coleta de dados; a utilização de vários instrumentos de coleta de dados; a análise de forma indutiva; o foco no significado dado pelos participantes; o plano inicial emergente da pesquisa - esta que é sujeita a sofrer alterações no decorrer do desenvolvimento do plano.

O trabalho ainda pode ser caracterizado como uma pesquisa participante, já que conta com envolvimento dos pesquisadores e dos pesquisados no processo, isto é, há uma colaboração entre os sujeitos. Sobre isso, Faerman (2014, p. 43) aponta que a pesquisa 
participante é uma das formas de "[...] aproximar o pesquisador do fenômeno a ser investigado e, igualmente, de construir o conhecimento acerca desse fenômeno".

O conjunto de atividades foi desenvolvido no âmbito de uma turma do primeiro ano do ensino médio de uma escola do sistema regular público de ensino, localizada no Sul de Minas Gerais, no ano de 2019. Ressalta-se que o projeto deste estudo foi submetido ao Comitê de Ética em Pesquisa (CEP), por meio de cadastro na Plataforma Brasil, do Ministério da Saúde, e sua aprovação se deu pelo Centro Universitário de Itajubá ${ }^{3}$.

$\mathrm{O}$ estudo foi estruturado em três fases e algumas foram realizadas simultaneamente. $\mathrm{Na}$ primeira fase, realizou-se estudo do referencial teórico relativo às potencialidades do uso das simulações computacionais e às dificuldades em utilizar tais recursos em aulas de Física.

$\mathrm{Na}$ segunda fase, elaborou-se um conjunto de atividades com o intuito de abordar conceitos de cinemática e dinâmica por meio das simulações computacionais. Para subsidiar a elaboração do conjunto de atividades, julgou-se importante realizar acompanhamento das aulas do professor regente, com o intuito de conhecer a dinâmica das aulas, a interação dos estudantes e a estrutura da instituição. Dessa forma, durante os meses de março e abril, a pesquisadora acompanhou as aulas do professor de Física da turma em questão.

Nessa fase foi possível elaborar e aplicar questionários com o professor responsável pelas aulas de Física e com a professora de apoio, visando compreender as dificuldades e potencialidades dos estudantes PAEE. Em paralelo, realizou-se a escolha das simulações computacionais, que deveriam ser de fácil acesso - funcionar sem o acesso à internet, devido à instabilidade da rede de internet da escola - e compatível com os recursos de acessibilidade dos computadores da escola.

Destaca-se que o conjunto de atividades foi desenvolvido por meio de intervenções, com o intuito de atender às dificuldades e potencialidades dos estudantes PAEE. Porém, a atividade foi desenvolvida com todos os estudantes da turma, partindo do pressuposto de que os recursos que auxiliam os estudantes PAEE podem beneficiar também os estudantes regulares.

Após a elaboração do conjunto de atividades e de um questionário, que tinha o intuito de compreender as concepções dos estudantes acerca da utilização das simulações computacionais, na segunda etapa desta investigação esse conjunto de atividades foi implementado com todos os estudantes. Nesse momento, realizou-se a coleta dos dados que, posteriormente, foram analisados.

No quadro a seguir é possível observar como se deu o desenvolvimento da implementação das atividades ${ }^{4}$, o tempo de aula, o conteúdo abordado, o objetivo das aulas e as competências e habilidades segundo a Base Nacional Comum Curricular (BNCC).

\footnotetext{
3 Aprovação sob o número Certificado de Apresentação de Apreciação Ética (CAAE) 11677219.6.0000.5094 e sob número do Parecer 3.304.894.

${ }^{4}$ O plano de aula utilizado na implementação do conjunto de atividades pode ser acessado por meio deste link: https://drive.google.com/drive/folders/1Nv19d_tdxOh0DUESILDiVUJuT7pBg2d3?usp=sharing
} 
Quadro 1: Estrutura das atividades desenvolvidas

\begin{tabular}{|c|l|l|l|l|}
\hline Atividade & $\begin{array}{c}\text { Tempo } \\
\text { de aula }\end{array}$ & $\begin{array}{c}\text { Conteúdo } \\
\text { abordado }\end{array}$ & \multicolumn{1}{c|}{ Objetivo } & \multicolumn{1}{c|}{ Competências e habilidades da BNCC } \\
\hline $\begin{array}{c}1^{\circ} \text { Conjunto } \\
\text { de } \\
\text { atividades }\end{array}$ & $\begin{array}{l}150 \\
\text { minutos } \\
\text { aceleração } \\
\text { movimento } \\
\text { retilíneo } \\
\text { uniformemente } \\
\text { variado }\end{array}$ & $\begin{array}{l}\text { Desenvolver os } \\
\text { conceitos sobre } \\
\text { movimento } \\
\text { retilíneo } \\
\text { uniformemente } \\
\text { variado }\end{array}$ & $\begin{array}{l}\text { Identificar diferentes movimentos que se } \\
\text { realizam no cotidiano e as grandezas } \\
\text { relevantes para sua observação; reconhecer } \\
\text { e utilizar símbolos, códigos e } \\
\text { nomenclaturas de grandezas da Física; e } \\
\text { compreender e utilizar leis e teorias } \\
\text { físicas. }\end{array}$ \\
\hline $\begin{array}{c}2^{\circ} \text { Conjunto } \\
\text { de } \\
\text { atividades }\end{array}$ & $\begin{array}{l}100 \\
\text { minutos }\end{array}$ & $\begin{array}{l}\text { Noções de força } \\
\text { e primeira lei de } \\
\text { Newton. }\end{array}$ & $\begin{array}{l}\text { Desenvolver os } \\
\text { conceitos } \\
\text { iniciais de força } \\
\text { e a primeira lei } \\
\text { de Newton. }\end{array}$ & $\begin{array}{l}\text { Conhecer e utilizar conceitos físicos; } \\
\text { relacionar grandezas; quantificar e } \\
\text { identificar parâmetros relevantes; e } \\
\text { compreender e utilizar leis e teorias } \\
\text { físicas. }\end{array}$ \\
\hline
\end{tabular}

Fonte: Elaborado pelas autoras.

Para a coleta de dados foram utilizados como instrumento os registros dos estudantes produzidos a partir das atividades propostas e do questionário -, registros de observações em diário de campo da pesquisadora e gravações em áudio. Os dois últimos elementos possibilitaram a análise dos argumentos expostos pelos estudantes no desenvolvimento das atividades.

$\mathrm{Na}$ terceira etapa houve a análise dos dados coletados, que seguiu as cinco fases propostas por Yin (2016, p. 167), a saber: compilar, decompor, recompor, interpretar e concluir. Sendo assim, em um primeiro momento foi atribuída uma ordem aos dados, que em seguida foram fragmentados e depois reorganizados; posteriormente realizou-se uma interpretação dos dados, a fim de extrair conclusões sobre eles.

Destaca-se que no processo de interpretação e análise, os dados coletados foram confrontados por meio de uma triangulação que, segundo Flick (2009), pode ser utilizada para "[...] ampliar o conhecimento de um tema ou para avaliar resultados de forma mútua" (p. 91). A triangulação foi composta com as diferentes fontes de dados já mencionadas, a saber: os registros dos(as) alunos(as), as observações descritas em diário de campo e a transcrição de alguns episódios gravados em áudio.

Como a pesquisa tem ênfase nos estudantes PAEE, aponta-se a relevância de uma breve descrição desses estudantes, para que o leitor compreenda o universo em que o estudo foi realizado. A turma contava com três estudantes com deficiência, os quais serão apresentados a seguir. Um com deficiência intelectual (DI), que, para preservar sua identidade, será denominado como E2. Ressalta-se que o estudante, segundo o professor regente, não apresentava limitações quanto ao ensino de Física e, durante o acompanhamento das aulas, foi possível perceber que ele interagia bem com os colegas e professores.

A classe contava também com a presença de um estudante que possui perda de $95 \%$ da visão, que terá o nome fictício de E1. Esse estudante foi o caso mais preocupante no acompanhamento realizado durante as aulas, pois devido às suas limitações, à falta de acessibilidade dos materiais utilizados e à metodologia de ensino utilizada, ele permanecia com a cabeça abaixada em sua carteira durante a aula, sem interagir com os estudantes e/ou professor.

O terceiro estudante público-alvo desta pesquisa apresenta um quadro de Transtorno do Espectro Autista (TEA) e será denominado como E3. Segundo os professores, o estudante não se interessava pelas disciplinas da área de exatas, alegando que não conseguia compreender o que estava sendo explicado. Ao que concerne à sua relação com os colegas e 
com o professor, pôde-se perceber que sua interação era limitada, visto que ele não conversava com os demais e todas as suas dúvidas eram direcionadas e sanadas pela professora de apoio. Ressalta-se ainda que o estudante com TEA era o único que tinha uma professora de apoio; no entanto, essa profissional também auxiliava os demais estudantes PAEE. No tópico a seguir, o conjunto de atividades desenvolvidas com os estudantes será descrito e analisado.

\section{Intervenção 1: Compreendendo os movimentos a partir de um homem em movimento}

A primeira intervenção realizada teve o intuito de compreender o modo como as simulações computacionais podem auxiliar os estudantes no estudo do conceito de Movimento Retilíneo Uniformemente Variado (MRUV). Para que os estudantes compreendessem o MRUV, era necessário que entendessem primeiramente o conceito físico da aceleração; para tanto, optou-se por uma abordagem de contextualização, na qual foi feita uma analogia com o cotidiano dos estudantes, o que possibilitou apresentar a Física como um conteúdo mais interessante e significativo para a vida do estudante.

Com o desenvolvimento da aula, em que foi proposta uma discussão sobre a comparação entre uma corrida de carros e a de uma bicicleta, foi possível perceber a curiosidade e o interesse de alguns estudantes, que ficaram instigados com a possibilidade de se trabalhar a Física a partir do movimento de uma bicicleta ou de um automóvel - o que ocorreu por meio da explicação sobre o conceito e a aplicação da aceleração. Sobre isso, os autores Wharta e Alário (2005) destacam que contextualizar é construir significados, que, no entanto, não são neutros, e incorporam valores porque explicitam o cotidiano, mostrando assim a importância de se relacionar conceitos científicos com a vivência dos estudantes, para que, desse modo, os conceitos possam fazer mais sentido.

Foi possível notar tal construção de entendimentos ao analisar as respostas dos estudantes para a questão 1, que tinha o intuito de levar os estudantes a definirem com suas palavras a aceleração. Apesar das respostas serem superficiais, entende-se que os estudantes já relacionavam a aceleração com a velocidade, conforme pode ser observado nos excertos apresentados no Quadro 2.

Quadro 2: Respostas dos estudantes sobre o que seria a aceleração

\begin{tabular}{|c|c|}
\hline Estudante & Fala do Estudante \\
\hline E1 & "A aceleração está ligada com a velocidade" \\
\hline E2 & "Esta (sic) acelerando, almento (sic) a velocidade" \\
\hline E3 & "Aceleração tem haver (sic) com a velocidade" \\
\hline
\end{tabular}

Fonte: Dados da pesquisa, 2019.

Ao utilizar a contextualização e relacionando o conceito físico da aceleração com o cotidiano dos estudantes, identificou-se a percepção correta da relação de dependência entre a velocidade e a aceleração, especialmente entre os estudantes com deficiência. Desse modo, evidencia-se que, ao utilizar a contextualização, torna-se viável construir conhecimentos científicos por meio dos conhecimentos prévios dos discentes. Sobre isso, Maffi et al. (2019) ressaltam que o papel da contextualização é possibilitar a relação dos aspectos do contexto em que se vive com a criticidade, para que dessa forma seja possível compreender esse contexto.

A fim de auxiliar os estudantes a compreenderem de fato o MRUV, foi elaborada uma atividade utilizando a simulação computacional "Homem em movimento", disponível no site Phet Interactive Simulations, da Universidade do Colorado, que oferece simulações 
Revista de Educação, Ciência e Tecnologia

computacionais interativas de Matemática e Ciências. A partir dessa simulação computacional, foi possível explorar o conceito do MRUV por meio das mudanças dos parâmetros, como: velocidade, espaço e aceleração, conforme a figura 1. Fundamentados nessa estratégia de ensino, foi possível proporcionar aos estudantes a possibilidade de analisar o movimento de uma pessoa, bem como os respectivos gráficos para os parâmetros selecionados.

A escolha dessa simulação computacional se justifica por ela ser de fácil acesso e por funcionar sem a necessidade de conexão a uma rede de internet - já que imprevistos com a rede de transmissão poderiam ocorrer durante o desenvolvimento das aulas -, além de apresentar uma interface autoexplicativa, o que possibilita a fácil manipulação por parte dos estudantes.

Figura 1-Interface da simulação computacional "Homem em movimento"

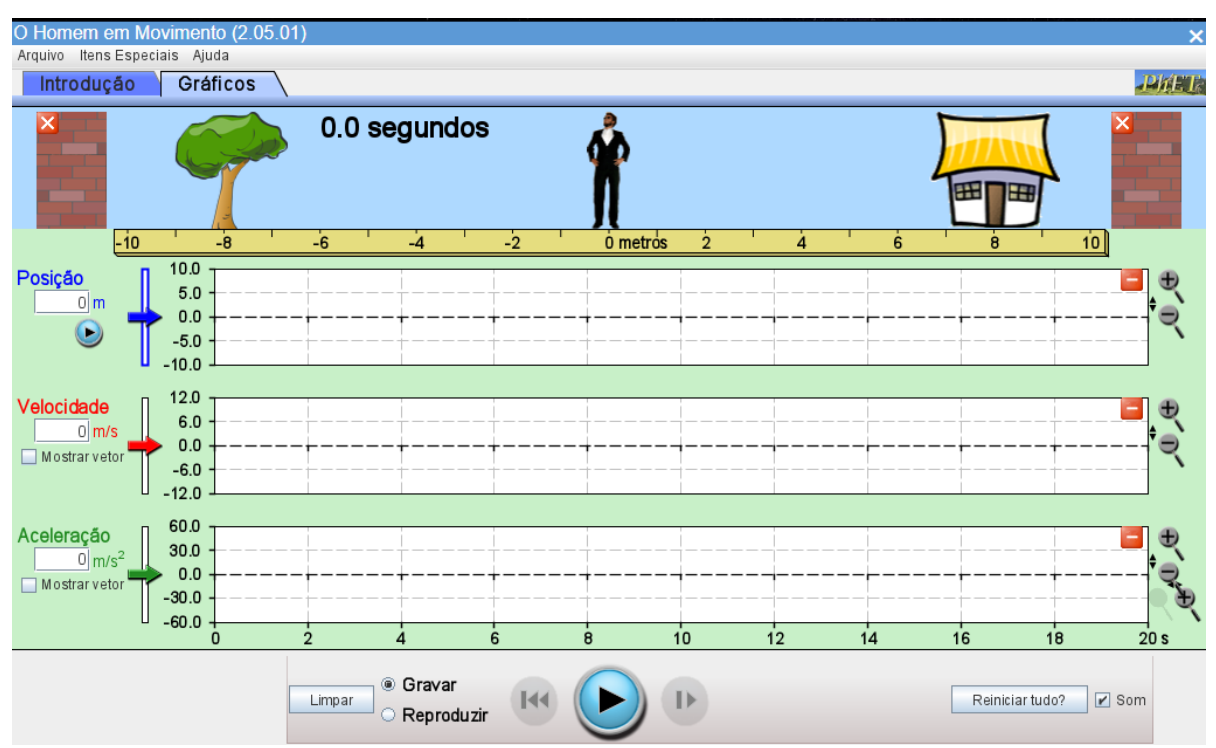

Fonte: Phet Interactive Simulations, 2019.

A atividade com o uso da simulação computacional foi realizada em duplas, no laboratório de informática da escola. Em um primeiro momento, foi destinado um período para que os estudantes pudessem conhecer e interagir com a simulação computacional, alterando seus parâmetros aleatoriamente.

Nesse instante foi possível perceber a empolgação do estudante E2, pois ele tomou a frente, em sua dupla, na alteração dos parâmetros, interagindo com a simulação computacional, fato que mostra como o uso das simulações computacionais pode despertar o interesse dos estudantes para conhecer o conceito envolvido.

Essa empolgação do estudante pode estar relacionada à metodologia de ensino escolhida, que apresenta conceitos por meio do lúdico. De acordo com Daguano e Fantacini (2012), o lúdico presente no processo de aprendizagem contribui de maneira prazerosa e eficaz para o desenvolvimento do conhecimento do estudante, explorando sua criatividade e possibilitando, desse modo, uma melhora no processo de ensino, uma vez que a ludicidade é uma boa estratégia para que a aprendizagem ocorra de forma efetiva.

Além disso, Kenski (2012) ressalta que o uso das TIC pode provocar alterações no comportamento dos estudantes, levando-os a melhorar o conhecimento e despertando neles o interesse em aprofundar o conteúdo abordado nas aulas, além de dinamizar o espaço de ensino e aprendizagem. Sendo assim, uma vantagem no uso de atividades lúdicas é a tendência em 
motivar o estudante a participar das atividades desenvolvidas em âmbito educacional, uma vez que o seu uso na sala de aula motiva o adolescente justamente por criar um ambiente de descontração, o que torna favorável a aprendizagem.

Foi perceptível também a empolgação do estudante com TEA (E3), indo ao encontro do que é defendido por Silva, Mouro e Soares (2017), uma vez que os estudantes com TEA demonstram interesse em manusear e utilizar recursos computacionais, como celulares, tablet, jogos eletrônicos, entre outros. Por conta disso, esses recursos se apresentam como uma importante possibilidade nos processos de ensino e aprendizagem, sobretudo dos estudantes com TEA.

O uso da simulação computacional teve como objetivo fazer com que os estudantes percebessem o modo como a velocidade está relacionada à aceleração pela alteração dos parâmetros, que permitia mudanças no movimento. Sobre isso, Medeiros e Medeiros (2002) destacam a necessidade de permitir que os estudantes formulem e testem suas hipóteses. Assim, foi proposto que os estudantes alterassem os parâmetros e organizassem os dados em uma tabela, por meio da qual puderam analisar e interpretar os dados, criando hipóteses e, no caso em questão, confirmar que a aceleração estava relacionada com a velocidade, o que já havia sido discutido anteriormente. Além disso, os estudantes foram questionados acerca da definição de aceleração. No quadro 3 é possível observar as respostas dos estudantes para essa questão.

Quadro 3: Respostas dos estudantes sobre a definição física da aceleração

\begin{tabular}{|c|c|}
\hline Estudante & Fala do Estudante \\
\hline E1 & $\begin{array}{c}\text { "A aceleração está ligada com a velocidade. Quando a aceleração } \\
\text { cresce, a velocidade também cresce." }\end{array}$ \\
\hline E2 & $\begin{array}{l}\text { "Quanto maior a aceleração, maior a velocidade em menor } \\
\text { tempo." }\end{array}$ \\
\hline $\mathbf{E 3}$ & $\begin{array}{c}\text { "Aceleração é a velocidade dividida pelo tempo, quanto mais } \\
\text { aceleração mais velocidade." }\end{array}$ \\
\hline
\end{tabular}

Fonte: Dados da pesquisa, 2019.

Diante das respostas é perceptível que, após a contextualização inicial e a interação com a simulação computacional, todos os estudantes sujeitos da pesquisa apresentaram considerações mais adequadas para a aceleração do ponto de vista da Física. Ressalta-se a resposta do estudante E3, que apresentou a relação matemática da velocidade, evidenciando que a aceleração seria o resultado da divisão da velocidade pelo tempo gasto.

Outros tópicos discutidos com o apoio da simulação computacional foram as respectivas equações do MRUV. Como a simulação computacional permite alterar os parâmetros, foi proposto que os estudantes deixassem a aceleração constante e analisassem como a velocidade se alterava com o passar do tempo.

A visualização do fenômeno e do gráfico sendo preenchido com o passar do tempo foi de suma importância para que os estudantes conseguissem perceber como a velocidade final estava relacionada com os outros parâmetros, como é possível observar nas respostas a seguir.

Quadro 4: Respostas dos estudantes sobre a relação entre velocidade e aceleração

\begin{tabular}{|c|c|}
\hline Estudante & Fala do Estudante \\
\hline E1 & "A velocidade final depende da aceleração e do tempo." \\
\hline E2 & "A velocidade final (...) a velocidade inicial mas (sic) o tempo." \\
\hline E3 & "A velocidade final é o tempo mais a velocidade inicial." \\
\hline
\end{tabular}

Fonte: Dados da pesquisa, 2019. 
Revista de Educação, Ciência e Tecnologia

Com base nas respostas, pode-se concluir que os estudantes conseguiram desenvolver, ainda de forma inicial, um pensamento sobre as variáveis envolvidas na determinação da velocidade final. Ressalta-se que, devido ao planejamento do professor regente, não foi possível realizar outra aula para aprofundar esse conceito, utilizando novamente as simulações computacionais e/ou outros recursos didáticos para deduzir corretamente as equações do MRUV.

No que concerne às atividades avaliativas, que constituíam uma demanda do professor regente das aulas de Física, as respostas apresentadas pelos estudantes PAEE não estavam completamente precisas - muitas vezes os alunos erravam a unidade de medida ou não a apresentavam, conforme exibido na Figura 2. Entretanto, entende-se que os estudantes PAEE compreenderam os conceitos e fenômenos físicos envolvidos, haja vista que conseguiram resolver a maioria das atividades e participaram efetivamente das aulas lecionadas.

Figura 2- Exemplo dos erros dos estudantes PAEE na atividade avaliativa

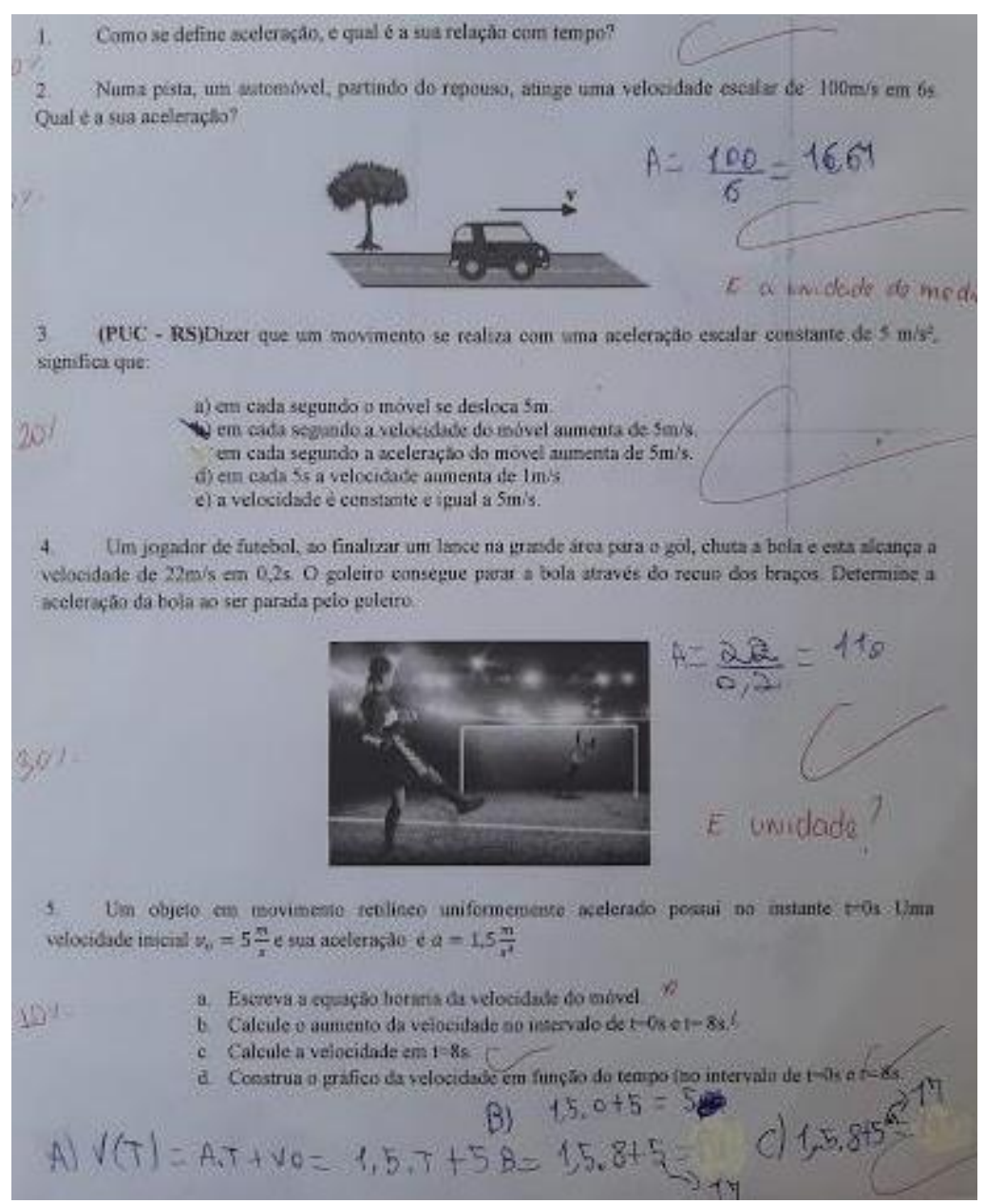

Fonte: Dados da pesquisa, 2019.

Entende-se, portanto, que a simulação computacional pôde configurar-se como um estímulo para a aprendizagem efetiva, pois ela torna ativo o estudante no processo de aprendizagem, permitindo a realização de atividades dinâmicas, lúdicas, interativas, exploratórias e contextuais, além de construir um significado sobre o conceito. 


\section{Intervenção 2: Simulando as forças}

Nessa segunda intervenção, foi planejada uma prática investigativa que consiste, segundo Azevedo (2004), em uma atividade na qual a ação do estudante não deve se limitar apenas a manipular ou a observar: ele deve refletir, discutir, explicar e relatar o que está sendo observado ou manipulado. Assim, a utilização da metodologia de ensino por investigação possibilita um ensino no qual o estudante tem um papel ativo na construção do seu próprio conhecimento. Por meio do desenvolvimento de uma atividade pautada na metodologia de investigação é possível proporcionar um cenário em que os estudantes elaborem com profundidade os conceitos, podendo dessa forma desenvolver uma aprendizagem efetiva sobre os conteúdos que estão sendo estudados (FREITAS ZOMPERO; LABURÚ, 2010).

Azevedo (2004) destaca ainda que as atividades investigativas devem fazer sentido para o estudante, de modo que ele saiba o motivo pelo qual está investigando os cenários e conceitos em questão. Com o intuito de trabalhar os conceitos iniciais de dinâmica na sala de aula, escolheu-se a simulação "Forças e Movimento", disponível no site do Phet Interactive Simulations, que aborda conceitos de força no cotidiano.

Essa simulação computacional é dividida em duas etapas. Em um primeiro momento, apresentou-se a simulação de um Cabo de Guerra, conforme apresentado na Figura 3.

Figura 3- Interface da simulação computacional Cabo de Guerra

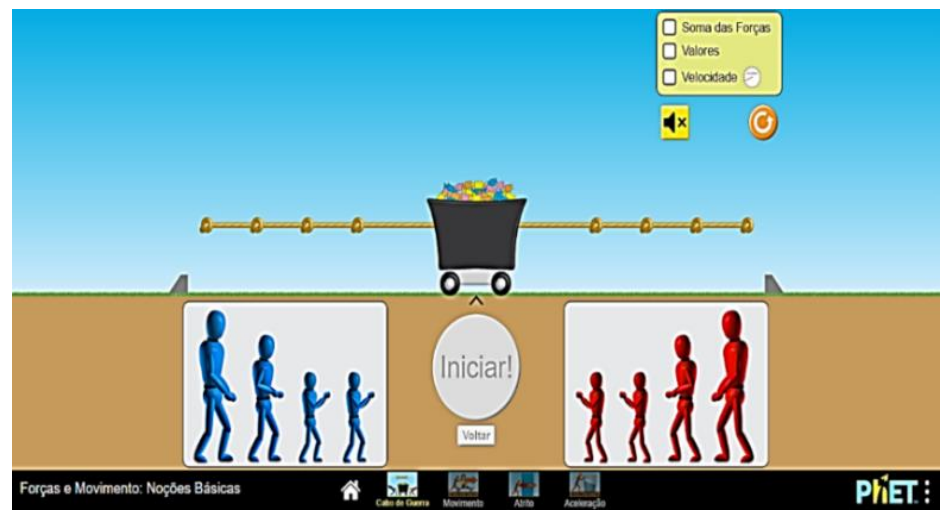

Fonte: Phet Interactive Simulations, 2019.

Em seguida, mudando a interface da simulação, foi possível interagir com outra simulação, com a possibilidade de empurrar objetos de diferentes massas e variar o atrito da superfície, conforme pode se observar na figura 4.

Figura 4- Interface da simulação computacional Movimento

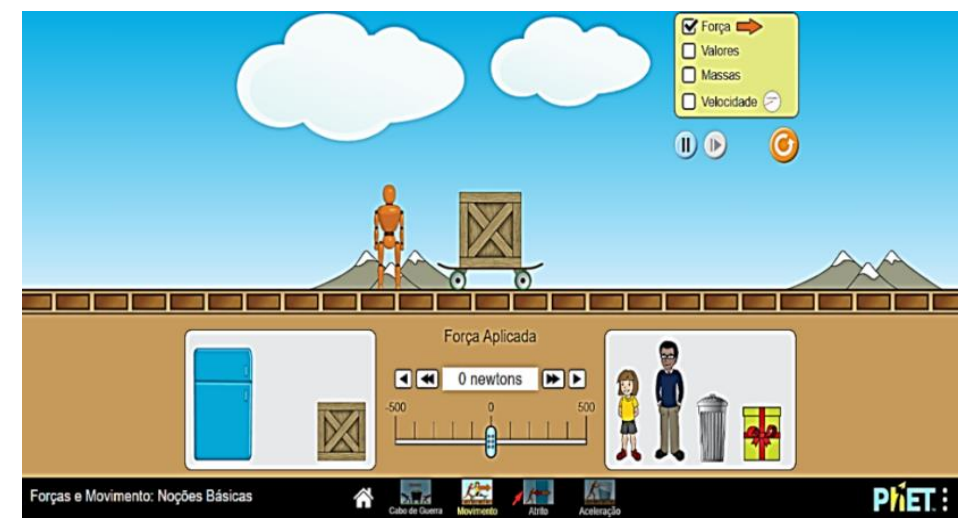

Fonte: Phet Interactive Simulations, 2019. 
A importância de atividades investigativas como ponto de partida para compreender conceitos está relacionada à possibilidade de levar o estudante a participar de seu processo de aprendizagem, relacionando os conceitos com os objetos de estudo e procurando uma explicação para determinado fenômeno (AZEVEDO, 2004). Nesse sentido, foi elaborado um guia no qual os estudantes deveriam responder a algumas questões, conforme interagiam e investigavam o que acontecia nas simulações computacionais, a fim de compreender os fenômenos envolvidos.

Assim como na intervenção anterior, a segunda também foi realizada na sala de informática. Primeiramente, foi proposto que os estudantes se separassem em trios, visto que alguns computadores da sala de informática não estavam funcionando. No entanto, durante a separação das equipes, o estudante com TEA (E3), devido à sua baixa interação social, preferiu ficar sozinho - inclusive sem sua professora de apoio, que auxiliou o estudante E1 a manusear a ferramenta de acessibilidade do notebook. Já o estudante E2 ficou junto aos seus colegas, sendo o responsável por alterar os parâmetros da simulação computacional.

Apesar do estudante E3 ter ficado sozinho, sobre sua interação com a pesquisadora e com a simulação, foi possível perceber que ele teve uma liberdade maior de sanar suas dúvidas com a pesquisadora e propor suas hipóteses no decorrer da atividade. Durante toda a investigação, a pesquisadora o incentivou a testar suas hipóteses no simulador, evidenciando dessa forma algumas vantagens da simulação, como favorecer a interação entre os estudantes e os professores, e o fato dos estudantes poderem construir seus conhecimentos com auxílio da simulação computacional, o que torna o processo de aprendizagem mais efetivo.

Isso vai ao encontro do que defende Moran (2006), ou seja, nas aulas em que as TIC são utilizadas, a principal função do docente é ser orientador/mediador: ajudar o estudante a interpretar os dados da simulação, contextualizá-los e relacioná-los. A partir da simulação computacional e do guia da atividade investigativa, ficou nítido que o estudante estava mais ativo, discutindo sobre cada questão e os conceitos físicos envolvidos. Ressalta-se, portanto, que as atividades investigativas requerem uma atividade intelectual mais ativa por parte dos estudantes, já que eles não recebem as informações prontas do professor.

Destaca-se que o guia elaborado foi dividido em duas partes: a primeira relacionada à simulação computacional do Cabo de Guerra e a segunda à simulação do Movimento, após a aplicação de determinada força. A primeira parte tinha o intuito de fazer com que os estudantes compreendessem o que era a força e, para isso, os estudantes foram levados a investigar, em uma questão, o que acontecia se fosse colocada a mesma quantidade de pessoas, ou seja, de força, dos dois lados do cabo de guerra.

Os estudantes então responderam que nada acontecia, justificando pelo fato de ter a mesma quantidade de pessoas, ou seja, de força sendo exercida, dos dois lados no Cabo de Guerra, conforme é possível observar nas respostas:

Quadro 5: Falas dos estudantes sobre a força exercida no cabo de guerra

\begin{tabular}{|c|c|}
\hline Estudante & Fala do Estudante \\
\hline E1 & "Não se move porque eles estão aplicando a mesma força em \\
ambos os lados."
\end{tabular}

Fonte: Dados da pesquisa, 2019.

Dessa forma, pode-se perceber que os estudantes PAEE, ao observarem a primeira situação no Cabo de Guerra, relacionaram o conceito de força com o movimento. Na questão 
seguinte, os estudantes foram indagados acerca da relação entre a força e a velocidade, e foram instigados a alterar o número de pessoas de um lado do cabo de guerra e a observar o que acontecia com a velocidade.

Nesse momento, eles tiveram certa dificuldade em relacionar a força com a velocidade e foi preciso recordar a relação entre o movimento e a velocidade, pois era mais nítida a relação entre a força e movimento - visto que, ao observarem a simulação computacional, os estudantes perceberam que, ao aplicar uma força no objeto, ele se movia. Após a explicação, as seguintes respostas foram obtidas:

Quadro 6: Falas dos estudantes sobre a força exercida após a explicação da relação entre movimento e força

\begin{tabular}{|c|c|}
\hline Estudante & Fala do Estudante \\
\hline E1 & "Não força para a esquerda, velocidade aumentando." \\
\hline E2 & "O vetor fica para a esquerda e velocidade aumenta." \\
\hline E3 & "A força do lado esquerdo é maior." \\
\hline
\end{tabular}

Fonte: Dados da pesquisa, 2019.

Com base nas respostas, é possível perceber que os estudantes se basearam na simulação para responder, já que é possível visualizar essas informações na interface da ferramenta. Assim, concluiu-se que os estudantes usaram as simulações para testarem suas hipóteses, bem como para desenvolver seu conhecimento. Esse resultado está em consonância com o pensamento de Azevedo (2004), pois, segundo o autor, os estudantes desenvolvem, por meio de uma atividade investigativa, diversas habilidades como argumentação, interpretação e análise do que está sendo observado.

A segunda parte do guia foi elaborada com o objetivo de desenvolver, juntamente com os estudantes, o conceito de Inércia. Para isso, os alunos foram questionados acerca da interferência do atrito no movimento, sendo induzidos a investigar o que acontece com a velocidade quando a força é zero e quando o atrito é adicionado. As respostas obtidas estão no Quadro 7.

Quadro 7: Respostas dos estudantes sobre a interferência do atrito na simulação computacional

\begin{tabular}{|c|c|}
\hline Estudante & Fala do Estudante \\
\hline E1 & "A velocidade aumenta depois a velocidade permanece." \\
\hline E2 & "O objeto vai continuar andando a menos que tenha um atrito." \\
\hline E3 & "O atrito influência (sic) na velocidade." \\
\hline
\end{tabular}

Fonte: Dados da pesquisa, 2019.

Foi possível perceber que, na resposta do estudante E1, já há indícios do que se conhece como a primeira lei de Newton: a inércia que explica o fato de todo corpo continuar em seu estado de repouso ou de movimento uniforme, a menos que seja forçado a mudar tal estado por forças imprimidas sobre ele - ou seja, que a velocidade desse corpo permanece constante se não houver influência do meio. Ressalta-se, ainda, que a fala do estudante pode estar relacionada a um conhecimento prévio, que é oriundo das suas vivências e experiências (TREVISAN, 1999), isto é, quando o estudante relaciona um conteúdo científico apresentado na simulação com um conhecimento do seu cotidiano.

Em seguida, os estudantes foram questionados sobre uma definição para o que estava acontecendo com o movimento apresentado na simulação computacional, e observou-se, pelas respostas obtidas, que os estudantes compreenderam aspectos relacionados à primeira lei de Newton, sem a pesquisadora precisar enunciar. No entanto, também é possível perceber que cada estudante descreveu essa lei de uma forma diferente, como apresenta o Quadro 8. 
Quadro 8: Respostas dos estudantes sobre a primeira Lei de Newton

\begin{tabular}{|c|c|}
\hline Estudante & Fala do Estudante \\
\hline E1 & "Quanto maior a força maior e a velocidade." \\
\hline E2 & "Ela vai perdendo velocidade." \\
\hline E3 & $\begin{array}{r}\text { "A força se mantém constante quando não há atrito, mas se } \\
\text { houver atrito a velocidade vai diminuindo aos poucos." }\end{array}$ \\
\hline
\end{tabular}

Fonte: Dados da pesquisa, 2019.

De acordo com as respostas obtidas, foi possível perceber que o E3 foi mais descritivo, e isso pode estar relacionado a uma de suas potencialidades, destacada pela professora de apoio - ela ressaltou que o aluno gosta de discutir, colocar suas ideias e analisar, e com o auxílio da simulação aliada à atividade investigativa, ele pôde colocar isso em prática.

\section{Concepções dos estudantes acerca da utilização das simulações computacionais}

Com o intuito de compreender as concepções dos estudantes sobre a utilização das simulações computacionais, ao final das intervenções foi proposto que os estudantes respondessem um questionário, no qual eles poderiam descrever suas respectivas opiniões sobre as intervenções realizadas. Analisando as respostas, foram constatadas as alegações de que as simulações computacionais - aliadas às metodologias de ensino - ajudaram a tornar o conteúdo menos abstrato e, consequentemente, o ensino de Física mais dinâmico e interativo, o que vai ao encontro do que é defendido por diversos autores, como Medeiros e Medeiros (2002) e Costa (2017). No quadro 9 são apresentados excertos dos estudantes PAEE.

Quadro 9: Respostas dos estudantes sobre a potencialidade das simulações computacionais

\begin{tabular}{|c|c|}
\hline Estudante & Fala do Estudante \\
\hline E1 & $\begin{array}{r}\text { "Vendo o desenho e os movimentos fica mais fácil de entender } \\
\text { ainda mais quando aumentou a imagem." }\end{array}$ \\
\hline E2 & "Eu gostei muito das atividades a aula foi muito legal." \\
\hline E3 & "A simulação foi importante para aprender na prática." \\
\hline
\end{tabular}

Fonte: Dados da pesquisa, 2019.

Dessa forma, é possível inferir que todos os estudantes, de alguma forma, elencaram alguma vantagem no uso das simulações computacionais para os processos de ensino e de aprendizagem. Ao observar a resposta do estudante E3, pode-se perceber que ela está em consonância com o referencial, pois o aluno ressaltou que é possível perceber, com o auxílio do simulador, como as coisas acontecem na prática, visto que um dos propósitos da simulação computacional é a representação de um fenômeno.

Nessa perspectiva, o estudante E1 traz também em sua resposta o fato de que, visualizando o fenômeno, foi possível aprender de forma mais efetiva. Ressalta-se que esse estudante tem uma limitação sensorial e, desse modo, como ressaltado por Giroto, Poker e Omote (2012), os recursos tecnológicos podem facilitar e, às vezes, superar algumas limitações que dificultam ou impedem o aprendizado. Portanto, percebe-se que as simulações computacionais, aliadas às ferramentas de acessibilidade, puderam favorecer um ensino mais igualitário para o estudante em questão.

No que concerne à resposta do estudante E2, que ressaltou o fato das simulações computacionais terem tornado seu processo de aprendizagem mais "legal", tal consideração pode estar relacionada ao fato das TIC estarem presentes no cotidiano da maioria dos estudantes e, por isso, eles terem domínio dessas ferramentas - o que pode motivar o estudo. 
Essa informação está em consonância com o que é defendido por Diniz (2001), ao ressaltar que a utilização do computador em sala de aula proporciona uma aprendizagem mais interessante, dinâmica e eficiente.

Pode-se ainda relacionar a motivação dos estudantes diante do conteúdo abordado ao fato de que, ao investigar os fenômenos físicos por meio da simulação computacional, o estudante torna-se autor e condutor do processo de aprendizagem. Ele sai de uma posição passiva, em que apenas recebe as informações e passa a ser um agente ativo na construção de seu conhecimento, o que o torna mais interessado pelo conteúdo lecionado.

\section{Considerações finais}

Esta investigação foi realizada com o intuito de compreender as potencialidades do uso das simulações computacionais para o processo de aprendizagem, com ênfase nos estudantes PAEE, nas aulas de Física de uma sala regular da educação básica. A pesquisa de campo ocorreu em uma turma de $1^{\circ}$ ano do Ensino Médio de uma escola pública localizada no Sul de Minas Gerais e, com o auxílio de diário de campo, questionários, atividades realizadaspelos estudantes e gravações, foi possível desenvolver o presente estudo.

Para a elaboração das intervenções, foram realizadas observações do campo de pesquisa, a fim de estudar o contexto encontrado e de buscar formas de intervenções adequadas. Foram também disponibilizados questionários para o professor regente e a professora de apoio, com o objetivo de compreender as potencialidades e dificuldades dos estudantes. Durante o período em que a pesquisadora esteve presente na escola, foram feitas intervenções com o uso das simulações computacionais, abordando os conceitos de cinemática e dinâmica.

Observou-se que, ao longo das intervenções lúdicas, os recursos tecnológicos favoreceram o processo de aprendizagem, trazendo significado para os conceitos que os discentes estavam estudando. Houve também a possibilidade de fazer com que o estudante saísse da posição passiva na construção do seu conhecimento, passando a ser um agente ativo - transição importante para uma aprendizagem efetiva, especificamente para os estudantes PAEE, já que demonstraram um maior interesse em participar das atividades e em questionar, a fim de sanar suas dúvidas.

Além disso, entende-se que os recursos e metodologia escolhidos viabilizaram que os estudantes aprendessem no seu ritmo, dinamizando o espaço, os processos de ensino e aprendizagem, e, consequentemente, favorecendo a inclusão dos estudantes com deficiência, já que, dessa maneira, pôde-se oferecer uma equiparação de oportunidades aos estudantes. Com relação ao estudante E1, percebeu-se que ele se beneficiou com os recursos tecnológicos: por meio deles foi possível usufruir da ferramenta da acessibilidade, que facilitou sua participação nas aulas e o ajudou a superar algumas limitações.

Em relação à aprendizagem do estudante E3, observou-se que ele demonstrou grande interesse pelas atividades, questionando o que era proposto e levantando hipóteses sobre o que poderia acontecer e quais seriam os conceitos físicos envolvidos. Quanto à sua interação, que era limitada, concluiu-se que, ao utilizar a simulação computacional e o guia, a comunicação com a pesquisadora aumentou. $\mathrm{O}$ estudante E2 apresentou facilidade em se comunicar desde o início, o que foi aproveitado durante as atividades em equipe - e foi possível perceber uma troca de conhecimento entre eles, que se embasaram na simulação para chegar a determinada conclusão. 
No que concerne à aprendizagem de conceitos da Física, analisada pela interação com os recursos tecnológicos e pelas atividades avaliativas, foi possível notar que as respostas dos estudantes não estavam corretas em sua totalidade, mas frequentemente demonstravam a compreensão dos conceitos e fenômenos físicos envolvidos, atingindo assim o objetivo das aulas lecionadas.

As respostas dos estudantes demonstraram algumas contribuições do uso de TIC em aulas de física, como despertar a motivação, aprender na prática e auxiliar na visualização dos fenômenos. Deve-se ressaltar que os recursos tecnológicos, por si só, não garantem o processo de aprendizagem dos estudantes - sua utilização em sala de aula deve ser planejada com objetivos didáticos.

Acerca da inclusão, é necessário pontuar que não basta que a escola insira o estudante em sala de aula. Para que a inclusão seja efetiva, é importante que os professores e a comunidade escolar trabalhem juntos. Além disso, é importante destacar a importância da formação adequada, para que os professores estejam em condições de promover a inclusão em âmbito educacional. Com o término desta pesquisa, entende-se que as estratégias didáticas, aliadas ao uso das tecnologias digitais, podem auxiliar no processo de inclusão dos alunos com deficiência em aulas de Física.

\section{Referências}

AZEVEDO, Maria Cristina P. Stella. Ensino por investigação: problematizando as atividades em sala de aula. In: CARVALHO, A. M. P. (org.). Ensino de ciências: unindo a pesquisa e a prática. São Paulo: Pioneira Thomson Learning, 2004. p. 19-33.

BRASIL. Base Nacional Comum Curricular. Brasília: MEC, 2017. Disponível em: http://basenacionalcomum.mec.gov.br/images/historico/BNCC_EnsinoMedio_embaixa_site_ 110518.pdf. Acesso em: 05 set. 2020.

BRASIL. Declaração de Salamanca: Sobre Princípios, Políticas e Práticas na Área das Necessidades Educativas Especiais, 1994, Salamanca-Espanha. Disponível em: http://portal.mec.gov.br/seesp/arquivos/pdf/salamanca.pdf. Acesso em: 03 set. 2020.

CAMACHO, Carmem Maria Lopes de Ponte. Recursos Tecnológicos e Motivação para a Aprendizagem. 2017. 122 f. Dissertação de Mestrado. (Docência e Gestão da Educação). Universidade Fernando Pessoa.

CRESWELL, Jonh W. Projeto de pesquisa: métodos qualitativo, quantitativo e misto. 2. ed. Porto Alegre: Artmed, 2007.

COELHO, Rafael Otto. O Uso da Informática no Ensino de Física de Nível Médio. 101. Dissertação (Mestrado em Educação) - Universidade Federal de Pelotas, 2002.

COLL, César; MONEREO, Carles. Educação e aprendizagem no século XXI: novas ferramentas, novos cenários, novas finalidades. In: COLL, César; MONEREO, Carles.

Psicologia da educação virtual: aprender e ensinar com as tecnologias da informação e da comunicação. Porto Alegre; Artmed, 2010. p. 15-46. 2010.

COSTA, Marcia. Simulações computacionais no ensino de física: revisão sistemática de publicações da área de ensino. In: IV Seminário Internacional de Representações sociais, subjetividade e Educação. Campina Grande, 2017. 
DAGUANO, Lilian Queiroz; FANTACINI, Renata Andrea Fernandes. O lúdico no universo autista. Linguagem acadêmica, v. 1, n. 2, p. 109-122, 2012.

DINIZ, Sirley Nogueira de Faria. O uso das novas tecnologias em sala de aula. 2001.188.

(Dissertação). Universidade Federal de Santa Catarina, 2001.

FAERMAM, Lindamar Alves. A pesquisa participante: suas contribuições no âmbito das ciências sociais. Revista Ciências Humanas, Taubaté/SP (UNITAU), v. 7, n. 1, junho, 2014.

FLICK, Uwe. Qualidade na pesquisa qualitativa. In: Qualidade na pesquisa qualitativa. Porto Alegre: Grupo A, 2009.

FREITAS ZOMPERO, Andréia.; LABURÚ, Carlos Eduardo. As atividades de investigação no Ensino de Ciências na perspectiva da teoria da Aprendizagem Significativa. Revista electrónica de investigación en educación en ciencias, v. 5, n. 2, p. 12-19, 2010.

GIROTO, Claudia Regina Mosca; POKER, Rosimar Bortolini; OMOTE, Sadão. Educação Especial, formação de professores e o uso das tecnologias de informação e comunicação: a construção de práticas pedagógicas inclusivas. In: GIROTO, Claudia Regina Mosca; POKER, Rosimar Bortolini; OMOTE, Sadão (org.) As tecnologias nas práticas pedagógicas inclusivas. Marília: Editora Cultura Acadêmica, 2012. p. 11-23.

KARAGIANNIS, Anastasios; STAINBACK, William; STAINBACK, Susan. Fundamentos do Ensino Inclusivo. In: STAINBACK,Susan; STAINBACK, William. Inclusão: um guia para educadores. Porto Alegre: Artmed, 1999. p. 21-34.

KENSKI, Vani Moreira. Educação e tecnologias: o novo ritmo da informação. 8. ed. Campinas, SP: Papirus, 2012.

MACÊDO, Josué Antunes; DICKMAN, Adriana Gomes. Simulações computacionais como ferramentas auxiliares ao ensino de conceitos básicos de eletricidade. In: XVIII SIMPÓSIO NACIONAL DE ENSINO DE FÍSICA. Anais... Vitória, 2009. p. 1-12.

MAFFI, Caroline. et al. A contextualização na aprendizagem: percepções de docentes de ciências e matemática. Revista Conhecimento Online, v. 2, n.1 p. 75-92, 2019. Disponível em:

https://periodicos.feevale.br/seer/index.php/revistaconhecimentoonline/article/view/1561/236

8. Acesso em: 24 ago. 2019

MANTOAN, Maria Teresa Eglér. Inclusão Escolar: o que é? por quê? como fazer? São Paulo: Moderna, 2003.

MEDEIROS, Alexandre; MEDEIROS, Cleide Farias. Possibilidades e limitações das simulações computacionais no ensino de Física. Revista Brasileira de Ensino de Física, São Paulo, v. 24, n. 2, p. 77-86, Jun/2002.

MENDES, Enicéia Gonçalves. A radicalização do debate sobre inclusão escolar no Brasil. Revista Brasileira de Educação, v. 11, n. 33, p. 387-405, set./dez. 2006.

MORAN, José Manuel. Ensino e aprendizagem inovadores com tecnologias audiovisuais e telemáticas. In: MORAN, José Manuel; MASETTO, Marcos Tarciso; BEHRENS, Marilda 
Aparecida (org.) Novas tecnologias e mediações pedagógicas. 10. ed. Campinas, SP:

Papirus, 2006.

PHET INTERACTIVE SIMULATIONS. Disponível em:

https://phet.colorado.edu/pt_BR/simulations/category/physics . Acesso em: 24 ago. 2019.

SILVA, Martony.; MOURA, Igo; SOARES, André. Uso de tecnologias computacionais para o ensino de crianças com Transtorno do Espectro Autista: Um mapeamento sistemático da literatura. In: Brazilian Symposium on Computers in Education, 2017. p. 173.

SOUZA, Amaralina Miranda. As Tecnologias da Informação e da Comunicação (TIC) na educação para todos. Educação em Foco. Juiz de Fora, edição especial, p. 349-366, fev/2015.

TREVISAN, Eunice Maria Castegnaro. Leitura e conhecimento prévio. Letras, n. 2, p. 22-32, 1991.

YIN, Robert K. Pesquisa qualitativa do início ao fim. Porto Alegre: Penso, 2016.

WARTHA, Edson José; SILVA, El da; BEJARANO, Nelson Rui Ribas. Cotidiano e contextualização no ensino de Química. Química nova na escola, v. 35, n. 2, p. 84-91, 2013.

Recebido em fevereiro de 2021.

Aprovado em maio de 2021. 